\title{
PANORAMA DO SETOR DE ENERGIA ELÉTRICA NO BRASIL E NO PARANÁ: POLÍTICAS E DESAFIOS PARA ENERGIAS ALTERNATIVAS ${ }^{1}$
}

\author{
Taíse Fátima Mattei ${ }^{2}$ \\ José Luiz Parré ${ }^{3}$
}

\begin{abstract}
RESUMO:
A energia elétrica é elemento essencial para a execução de praticamente todas as atividades dos seres humanos. Mas a maneira como ela é gerada pode causar impactos severos ao meio ambiente. Este artigo faz um panorama do setor de energia elétrica no Brasil e no estado do Paraná com intuito de analisar políticas e desafios para a geração de energias alternativas, consideradas sustentáveis do ponto de vista ambiental e econômico. Consiste em uma análise de revisão da literatura com pesquisa bibliográfica. Os principais resultados revelam que o Brasil vem diminuindo a dependência das fontes hídricas, mas ainda precisa investir para ampliar as fontes alternativas. O Brasil está diminuindo a emissão de poluentes no setor de eletricidade, mas o mesmo não vem ocorrendo no estado do Paraná. As principais políticas energéticas criadas até hoje com intuito de incentivar as fontes alternativas foram o PROINFA e o PAC em âmbito nacional, e o Programa Paranaense de Energias Renováveis e Projeto Smart Energy, no estado do Paraná. O Brasil, assim como o Paraná, tem elevado potencial para desenvolver fontes menos poluentes para geração de energia. É preciso coordenação entre as políticas e planejamento a médio e longo prazo.
\end{abstract}

Palavras-chave: Energias Renováveis. Energia Eólica. Energia Solar.

\section{OVERVIEW OF THE ELECTRICITY SECTOR IN BRAZIL AND PARANÁ: POLICIES AND CHALLENGES FOR ALTERNATIVE ENERGIES}

\begin{abstract}
Electricity is an essential element for the execution of practically all the activities of human beings. But the way it is generated can have severe impacts on the environment. This article provides an overview of the electric energy sector in Brazil and the state of Paraná in order to analyze policies and challenges for the generation of alternative energies, considered sustainable from an environmental and economic point of view. It consists of an analysis of the literature review with bibliographic research. The main results reveal that Brazil has been reducing its dependence on water sources, but it still needs to invest to expand alternative sources. Brazil is reducing the emission of pollutants in the electricity sector, but the same has not been happening in the state of Paraná. The main energy policies created to date to encourage alternative sources were PROINFA and PAC at the national level, and the Paranaense Renewable Energy Program and Smart Energy Project, in the state of Paraná. Brazil, like Paraná, has a high potential to develop less polluting sources for energy generation. Coordination between policies and planning is required in the medium and long term.
\end{abstract}

Keywords: Renewable energy. Wind energy. Solar energy.

\footnotetext{
${ }^{1}$ Agradecimento à CAPES pela concessão de bolsa de doutorado cuja parte da tese resultou neste artigo.

${ }^{2}$ Doutora em Teoria Econômica pelo Programa de Pós-Graduação em Ciências Econômicas - PCE - da Universidade Estadual de Maringá. Mestra em Gestão e Desenvolvimento Regional pela Universidade Estadual do Oeste do Paraná (UNIOESTE) campus de Francisco Beltrão. Bacharela em Ciências Econômicas pela Universidade Estadual do Oeste do Paraná (UNIOESTE) campus de Francisco Beltrão. Professora Substituta no Instituto Federaldo Paraná, campus de Palmas. Email: taise_mattei_slo@hotmail.com Orcid: https://orcid.org/0000-0003-3899-375X

${ }^{3}$ Professor Titular do Departamento de Economia da Universidade Estadual de Maringá (UEM) e do Programa de Pós-graduação em Economia (PCE/UEM). Graduado em Engenharia Agronômica pela Universidade Federal de Viçosa, Mestre e Doutor em Economia Aplicada pela Universidade de São Paulo (ESALQ/USP). Email: jlparre@uem.br Orcid: https://orcid.org/0000-0002-1569-8224
} 


\section{INTRODUÇÃO}

A vida dos seres humanos é afetada pela qualidade do ar, da água, dos solos, pela diversidade de espécies e pelas condições climáticas. O crescimento econômico influencia os recursos naturais de diversas maneiras. A emissão de poluentes afeta a atmosfera global, especificamente aqueles que contribuem ao esgotamento da camada de ozônio e ao efeito estufa. As principais fontes de poluentes são: queima de combustíveis fósseis, geração de eletricidade e aquecimento doméstico, fundição de minérios não-ferrosos, escape de automóveis, processos industriais e certos fabricantes de produtos químicos. Além disso, o desmatamento e a exaustão dos recursos provocam alterações no clima. Porém, ainda tem-se muita incapacidade em avaliar os efeitos do crescimento econômico sobre a qualidade ambiental.

O uso de combustíveis fósseis para geração de energia é causador de muitos problemas ambientais. A escassez desses recursos somados com a degradação ambiental tem levado a humanidade a encontrar fontes alternativas. Segundo Vichi e Mansor (2009), o século XXI iniciou com uma preocupação maior com relação ao meio ambiente e energia, devido principalmente aos problemas do efeito estufa e aquecimento global. É extremamente importante o desenvolvimento de fontes de energias alternativas visando o equilíbrio de longo prazo, dado que os recursos naturais são escassos e a população e as cidades crescem amplamente no tempo. A sustentabilidade do setor de energia elétrica garantirá cada vez mais o acesso desse recurso para as pessoas e o crescimento e desenvolvimento econômico das próximas gerações.

A energia elétrica é fundamental para a existência e manutenção da vida humana. Ela possibilita acesso a bens e serviços e viabiliza praticamente todas as atividades econômicas. A maneira como a energia elétrica é gerada e consumida causa diferentes impactos no meio ambiente e afeta o desenvolvimento sustentável de qualquer país. Embora não exista uma forma de geração de energia totalmente limpa, fontes menos poluentes de gases do efeito estufa e que causem menos problemas ambientais devem ser preferíveis.

Energias alternativas como eólica, solar e de biomassa são menos poluentes que outras formas de energia, causam menos impactos ambientais e são mais sustentáveis, e por isso devem ser preferidas. A energia eólica possui uma vantagem de não gerar materiais poluentes e ser abundante e renovável. A energia solar, por usa vez, é uma fonte perene, silenciosa, gratuita e não poluente, além de ser fonte de vida para várias espécies. Já a energia gerada a partir da biomassa, que pode ser de resíduos agrícolas e florestais, tem a vantagem de apresentar baixos custos de armazenamento. No entanto, as fontes alternativas ainda são mais caras e possuem menor potencial 
de geração de energia. Por isso, o desafio da sociedade moderna é desenvolver tecnologias para melhorar a matriz renovável e preservar o meio ambiente (GUENA, 2007).

Diante disso, o objetivo deste trabalho é traçar um panorama do setor de energia elétrica no Brasil e no estado do Paraná a fim de analisar as políticas e desafios para a geração de energia por meio de fontes alternativas. Dada a importância do setor de energia elétrica, torna-se necessário analisá-lo com a perspectiva de identificar as políticas e desafios para garantir a sustentabilidade energética e preservar os recursos para as futuras gerações.

Em 2020, de acordo com a ANEEL (2020), aproximadamente 61,04\% da potência instalada para geração de energia elétrica do Brasil era oriunda de energia hidráulica, 14,70\% era fóssil, 8,66\% eólica, 8,41\% biomassa (lenha, bagaço da cana e lixívia $)$, 1,50\% solar e 1,13\% nuclear. O Brasil era o terceiro país em geração de energia hidrelétrica em 2015, ficando atrás apenas da China e Canadá, e sétimo na geração de energia por fontes alternativas. Em 2017, segundo a EPE (2018), a região Sul consumia 18,2\% da energia do Brasil. Dos estados da região Sul, o estado do Paraná era o que mais consumia energia em 2017, com participação de 36,1\%. Na geração de energia o estado do Paraná foi destaque como o maior gerador de energia há vários anos em função da Usina Hidrelétrica de Itaipu, situada em parte no seu território. O desafio da geração de energia, não só do Brasil, mas de todo o mundo, é a utilização de fontes de energia limpas e renováveis em busca da sustentabilidade ambiental. Busca-se reduzir o impacto ambiental e, ao mesmo tempo, ser capaz de suportar o crescimento econômico (EPE, 2018). A utilização de fontes alternativas permite reduzir a dependência de combustíveis fósseis, gás natural e carvão para geração de energia, contribuindo para redução das emissões de gases do efeito estufa.

O artigo está organizado em 5 seções. A primeira apresenta esta introdução e a seção 2 trás a revisão da literatura mencionando a evolução histórica da energia elétrica no Brasil e no estado do Paraná. A seção 3 descreve brevemente a metodologia e a seção 4 mostra os resultados da pesquisa. Na seção 5 estão as considerações finais do trabalho.

\footnotetext{
${ }^{4}$ Do processamento da madeira no processo de extração da celulose é possível extrair a lixívia negra (ou licor negro) que é usado como combustível em usinas de co-geração da própria indústria de celulose.
} 


\section{REVISÃO DA LITERATURA}

\subsection{ENERGIA ELÉTRICA NO BRASIL}

A eletricidade no Brasil iniciou-se no período imperial com Dom Pedro II articulando a instalação de aparelhos para iluminação pública na cidade do Rio de Janeiro. Em 1883 entrou em funcionamento a primeira usina hidrelétrica de pequeno porte, em Diamantina, Minas Gerais. A geração de energia elétrica nesse período contou com a participação de pequenas empresas privadas e nacionais e até mesmo com empresas de governos municipais (GOMES et al. 2002; GASTALDO 2009; SILVA, 2011).

Com o fim do Império e a instituição da República em 1889, foi promulgada a Constituição de 1891 estabelecendo que as concessões de serviços de eletricidade deveriam ser aprovados pelas prefeituras municipais e que os estados poderiam aproveitar o potencial hídrico para geração de energia (SILVA, 2011). Gomes et. al (2002) apontam que entre 1883 e 1900 o Brasil elevou de maneira drástica a sua capacidade produtiva de energia, passando de $91 \mathrm{kWh}$ para $10.850 \mathrm{kWh}$, sendo que mais de $50 \%$ foi de origem hidráulica.

No início do século XX empresas estrangeiras começaram a participar do setor permitindo o aumento da geração de energia e fornecimento para consumo urbano e industrial próximo as unidades geradoras. $\mathrm{O}$ crescimento do setor elétrico aliou-se com o desenvolvimento econômico motivado pela economia cafeeira do período, que impulsionava a criação de ferrovias, a expansão urbana e as atividades comerciais, industriais e de serviços (LORENZO, 2001).

Segundo Silva (2011), a partir de 1920 a demanda por eletricidade se elevou no Brasil devido aos excedentes de renda agrícola que começaram a ser investidos na indústria, gerando também expansão dos centros urbanos. Foi criada então a Comissão Federal de Forças Hidráulicas, o primeiro órgão oficial ligado a política para o setor (SILVA, 2011). Nesse período, houve um processo de concentração em torno das empresas estrangeiras que acabaram adquirindo várias empresas privadas nacionais e municipais. Por conta disso, ocorreu significativo avanço técnico na construção de centrais elétrica, permitindo o aumento da oferta de eletricidade (LORENZO, 2001).

A crise da década de 1930, no entanto, alterou os rumos das várias economias no mundo, dentre elas o Brasil, ao passo que reduziu as exportações, diminuiu os termos de troca e cessou a 
entrada de capitais internacionais. Nesse mesmo período o Brasil passou pelas crises do setor cafeeiro, e precisou da atuação forte do Estado para se recuperar. Esse período foi marcado pela redefinição do papel do Estado, objetivando diversificar a estrutura produtiva com crescente intervencionismo (GOMES et al. 2002; SILVA, 2011).

O principal marco institucional no setor elétrico brasileiro nesse período se deu com a criação do Código das Águas por meio do Decreto 24.643 de 1934. Foi uma intervenção estatal no setor que autorizou as concessões para exploração dos serviços de energia elétrica e determinou as tarifas e as competências do Estado. O poder público passou a ter a responsabilidade de legislar e outorgar sobre as concessões de serviços públicos de energia elétrica, assim como a exploração da energia hidráulica, e os serviços de geração, transmissão e distribuição de energia (BRASIL, 1934; LORENZO, 2001).

Em 1939, em meio à falta de energia em várias partes do Brasil, o Decreto-Lei 1.285 criou o Conselho Nacional de Águas e Energia Elétrica (CNAEE). Esse órgão tinha como objetivo a centralização dos estudos de energia elétrica no Brasil e regulamentou o Código das Águas, impondo a revisão dos contratos e concessões existentes. A partir dos anos de 1940 começou a surgir alguns órgãos e entidades regionais e também a criação de usinas de geração de energia. Algumas regulamentações mais rígidas com relação à fixação de tarifas acabaram desestimulando o setor privado estrangeiro, passando grande parte dos investimentos para as mãos do Estado, que começou a atuar diretamente na geração de energia. Além disso, as incertezas do período contribuíram para desencorajar os investimentos estrangeiros (GASTALDO, 2009).

No fim da década de 1940 e início da década de 1950, passado o primeiro governo de Vargas no Brasil, começa a ocorrer certa flexibilização com intuito de não inviabilizar novos investimentos nos setores de infraestrutura. Sendo assim, alguns planos e projetos foram elaborados com o objetivo de desenvolver o setor energético. No governo de Juscelino Kubitschek, de 1956 a 1961, foram criadas a maior parte das companhias estaduais de energia elétrica: Espírito Santo Centrais Elétricas (ESCELSA) em 1965, Centrais Elétrica do Maranhão (CEMAR), Companhia Elétrica de Alagoas (CEAL), e a Companhia de Eletricidade do Estado da Bahia (COELBA), em 1959. Esse governo teve como papel central acelerar o desenvolvimento econômico do país por meio do Plano de Metas (GOMES et al. 2002; GASTALDO 2009; SILVA, 2011).

Nas décadas de 1960 e início de 1970, a conjuntura econômica favorável permitiu amplos investimentos e novos interesses externos no setor elétrico, consolidando o Estado como agente financiador e executor da política de infraestrutura brasileira. Nesse período foram criadas as Usinas de Itaipu e Tucuruí, o Programa Nuclear e a Ferrovia do Aço, além do Ministério de Minas 
e Energia através da Lei 3.782 de 1960. Em 1961 foi criada a Eletrobrás cujo objetivo era contribuir para aumentar a capacidade instalada do Brasil na geração de energia elétrica (GASTALDO, 2009).

No entanto, as crises do petróleo no início e fim da década de 1970 e o aumento das taxas de juros internacionais contribuíram para a reversão dos investimentos brasileiros e rápida transformação no cenário econômico. A política fiscal no período tornou-se bastante restritiva, a carga tributária elevada e os investimentos públicos reduzidos. Na década de 1980 o cenário mundial se agravou e o Brasil entrou num período de recessão, com a dívida pública em níveis alarmantes. O Estado reduziu sua capacidade de investimento e o setor energético foi comprometido, reduzindo a eficiência das empresas públicas (GASTALDO, 2009). O consumo de energia, por outro lado, continuou se expandindo na década de 1980 em função da maturação dos investimentos implementados no final da década de 1970 (PIRES, GOSTKORZEWICZ, GIAMBIAGI, 2001).

No início dos anos 1990 os problemas do setor elétrico brasileiro persistiam principalmente relacionados às dificuldades de financiamento, impedindo o aumento e expansão da sua capacidade, somados à falta de energia em algumas regiões. $\mathrm{O}$ estado endividado não tinha condições de executar planos de correção e expansão. A fim de resolver o problema, os governos da época de Fernando Collor de Mello e Itamar Franco promoveram diversas privatizações, permitindo que o setor privado começasse a atuar novamente no setor. As privatizações do setor de energia elétrica aconteceram, no entanto, apenas a partir de 1995. Além disso, dentro desse processo de reformulação, o governo dividiu o setor em vários segmentos: geração, transmissão, distribuição e comercialização (GOMES et al., 2002; FRANCISCO, 2012).

No período de 1980 até os anos 2000, o Brasil praticamente enfrentou uma situação de esgotamento da capacidade ociosa de infraestrutura elétrica existente, isso porque o consumo de energia cresceu a taxas crescentes enquanto a capacidade instalada do sistema foi decrescente (PIRES, GOSTKORZEWICZ, GIAMBIAGI, 2001).

O sucesso do Plano Real em conter a inflação nos anos 1990 teve impacto no setor elétrico. A apreciação cambial e a abertura comercial controlaram a inflação, mas acabaram deteriorando os termos de troca brasileiros. Isso acabou acelerando o processo de privatização, o que marca nesse período a retomada dos investimentos produtivos do setor privado (SILVA, 2011).

No início dos anos 2000, o Brasil enfrentou uma grave crise de energia elétrica causada pela queda dos reservatórios das usinas hidrelétricas, mudanças estruturais ocorridas no setor e 
problemas de infraestrutura e falta de investimentos. As concessionárias de energia estavam passando por problemas de endividamento que prejudicava a universalização do acesso dos serviços de energia elétrica. Isso acionou o alerta para a necessidade de novos investimentos em fontes alternativas de energia. O Ministério de Minas e Energia (MME) passou a se responsabilizar pelo planejamento e desenvolvimento de políticas para o setor, quando a partir de então foi criada a Empresa de Pesquisa Energética- EPE (FRANCISCO, 2012). Foi criada também pelo então presidente Fernando Henrique Cardoso a Comissão de Análise do Sistema Hidrotérmico de Energia Elétrica e a Câmara de Gestão da Crise de Energia Elétrica-CGCE em maio de 2001. Ambos foram incumbidos de avaliar o problema existente de desequilíbrio entre oferta e demanda de energia (SILVA, 2011).

A partir desse período, percebeu-se a continuidade da participação ativa do setor público no novo modelo regulatório do setor elétrico brasileiro. O objetivo era concretizar o papel do governo como promotor da eficiência alocativa e dinâmica. As principais medidas tomadas foram no sentido de corrigir as falhas estruturais do setor, mas também foi preciso vários racionamentos de energia que acabou reduzindo as receitas das empresas de energia, gerando crise no setor. Devido a esse contexto, o governo acabou tendo que assinar o Acordo Geral do Setor Elétrico permitindo a Recomposição Tarifária Extraordinária- RTE em que foram reajustadas as tarifas de todas as classes de consumo (SILVA, 2011).

A mudança presidencial a partir de 2002, em que assumiu Luis Inácio Lula da Silva, foi sob euforia do mercado externo. No entanto, as medidas tomadas pelo presidente conseguiram acalmar os ânimos, reduzir o câmbio, conter a inflação e fazer o PIB voltar a crescer. O novo governo propôs uma reforma para o setor de energia, continuando com projetos e estudos para combater a crise de energia. Identificaram que os principais problemas estavam na incapacidade de atração de investimentos externos e elevação das tarifas (SILVA, 2011). A Lei 10.848 de 2004 instituiu um novo modelo de governança no setor de energia, alterando várias atribuições dos órgãos já existentes e firmando objetivo de expandir a oferta de energia elétrica (BRASIL, 2004).

De modo geral, no Brasil, até metade da década de 1990, o modelo institucional do setor elétrico brasileiro era baseado na atuação forte do estado, regulando e controlando a geração, transmissão e distribuição de energia. A partir de então, houve duas mudanças importantes. Pós 1996 ocorreu privatizações de companhias operadoras de energia e o governo deixou de exercer papel de principal investidor, passando a dividir com a iniciativa privada a responsabilidade pela expansão do sistema elétrico. O estado ficou com o papel apenas de regular as atividades no 
mercado. No entanto, a partir dos anos 2000, foi introduzido o Novo Modelo do Setor Elétrico, em que o estado retomou o controle do planejamento do setor de energia elétrica. O objetivo dessa nova fase seria estabelecer um marco regulatório para garantir os incentivos adequados aos novos investimentos, preservar os interesses dos diversos agentes do setor elétrico e consumidores, e promover o bem-estar e a eficiência econômica.

\subsection{ENERGIA ELÉTRICA NO PARANÁ}

O estado do Paraná, assim como o Brasil de modo geral, apresenta grande potencial hídrico devido às características geomorfológicas, presença de rios de planalto, altos declives, corredeiras e vales. Isso explica o fato de, ao longo do tempo, os investimentos terem sido para geração de energia por fonte hídrica.

O primeiro registro de eletricidade no estado do Paraná foi em 1886 com a instalação de uma lâmpada para iluminação pública em Curitiba (ORTEGA, 2016). Mas a primeira usina de eletricidade no estado do Paraná foi iniciada em 1890 na cidade de Curitiba quando o presidente da Intendência Municipal de Curitiba, Dr. Vicente Machado, assinou contrato com a Companhia de Água e Luz do Estado de São Paulo para uma concessão de 20 anos. A usina ficou pronta em 1892 e gerava energia a vapor por meio da queima de madeira (COPEL, 2018a).

A segunda cidade paranaense a receber o serviço de eletricidade foi Paranaguá em 1902 quando a família Blitzkow instalou um sistema de geração com dois grupos a vapor. Dois anos mais tarde Ponta Grossa recebeu eletricidade, seguido de União da Vitória, graças a um acordo firmado entre a prefeitura local e o comerciante Grollmann (COPEL, 2018a).

Em 1910 foi inaugurada a primeira usina hidrelétrica do estado, a Usina de Serra da Prata, em Paranaguá. Essa usina esteve em funcionamento até o início da década de 1970 quando foi desativada. Em 1911 entrou em funcionamento em Ponta Grossa a Hidrelétrica de Pitangui, que ainda hoje está em operação, e é a mais antiga usina do parque gerador próprio da COPELCompanhia Paranaense de Energia Elétrica. Outras centrais hidrelétricas continuaram a ser instaladas no estado, mas somente em 1930 foi inaugurada uma usina considerada grande para os padrões da época, a de Chaminé, implantada na Serra do Mar nas proximidades de Curitiba. A usina foi ampliada e também permanece em operação até hoje (COPEL, 2018a).

Na década de 1930 foi criado o Serviço de Energia Elétrica do Paraná, que mais tarde transformou-se no Departamento de Águas e Energia Elétrica- DAEE. Todos os investimentos da 
FAZ CIÊNCIA, VOL. 23, N. 38, JUL/DEZ DE 2021 - P. 53 - 77

época se respaldavam no Código de Águas (instituído pelo Decreto-Lei número 24.463 de 10 de julho de 1934) e no Conselho Nacional de Águas e Energia Elétrica (Lei número 1.285 de 1939), que determinavam a coordenação do setor pelo poder público (COPEL, 2018a).

No fim da década de 1940 o estado do Paraná contava com atuação de várias empresas privadas de energia elétrica: Companhia Força e Luz do Paraná que atendia o entorno da região de Curitiba; Empresa Sul Brasileira de Eletricidade que atendia o Sul do Estado (regiões da Lapa, Rio Negro e Campo do Tenente); Empresa de Eletricidade Alexandre Schlemm que atendia União da Vitória e Porto União; Companhia Prada de Eletricidade que abastecia as cidades de Ponta Grossa, Castro e Piraí do Sul; Companhia Hidro Elétrica do Paranapanema que fornecia energia a 20 municípios do Norte Pioneiro; e Empresa Elétrica de Londrina S.A. que abastecia as cidades de Londrina, Arapongas, Cambé, Ibiporã, Rolândia e Jataizinho (COPEL, 2018a). Em 1954 foi criado a COPEL, empresa estatal de economia mista que deveria assumir gradativamente a responsabilidade pelos serviços de energia no Paraná, até então sob a responsabilidade do DAEE, prefeituras e concessionárias particulares (SOUZA, 1996; COPEL, 2018a).

A partir da década de 1950, a política que o governo do Paraná estabeleceu foi no sentido de retomar os investimentos na estrutura econômica, social e política do estado. A energia elétrica entrou nesse processo de planejamento visando a industrialização do estado, pois era vista como item fundamental. Até então, praticamente não existia um sistema elétrico no estado e a oferta de energia não conseguia acompanhar o aumento da demanda motivada também pela crescente urbanização (SOUZA, 1996).

Nas décadas de 1960 e 1970 várias usinas hidrelétricas de menor porte foram construídas no estado de acordo com a política de eletrificação rural. Essas obras tiveram parceria com as grandes cooperativas agrícolas do Paraná, como a Wittmarsum de Palmeira, a Coamo de Marechal Candido Rondon, a Agrária de Campo Mourão, a Arapoti de Guarapuava-Entre Rios, entre outras (MAGALHÃES, 2017).

Também na década de 1970, no período da ditadura militar no Brasil, iniciou-se a construção da Usina Hidrelétrica de Itaipu, conhecida como Itaipu Binacional por estar em terras paranaenses e do país vizinho Paraguai. Atualmente é a segunda maior usina do mundo, perdendo apenas para a Usina de Três Gargantas na China, mas por muito esteve na primeira posição (COPEL, 2018a). 
Os anos 1980 foram marcados por uma forte desaceleração na tendência de expansão do setor produtivo nacional. Mas, ainda assim, a economia paranaense apresentou moderado dinamismo crescendo a taxas superiores às da brasileira. O governo do estado optou pela construção de grandes hidrelétricas mesmo em períodos de recessão econômica do país, que exigiram grandes investimentos públicos (COPEL, 1982).

A situação econômica da década de 1980 somada a crise da dívida externa obrigou o estado a contrair novos empréstimos internacionais. Além disso, criou-se um consenso sobre a necessidade de substituir as fontes de energia não renováveis pela energia advinda de hidrelétricas dado o potencial hídrico do estado. A usina hidrelétrica Governador Ney Braga começou a ser construída no final do regime militar, 1981-1982, e foi a primeira hidrelétrica a submeter o projeto de construção a um estudo de impacto socioambiental (COPEL, 1982).

No início dos anos 2000, os empreendimentos do setor de energia continuaram no estado do Paraná. Foram construídas várias usinas de médio e pequeno porte, tanto térmicas como hidráulicas, também por iniciativa de produtores independentes de energia. As principais foram as Hidrelétricas de Santa Clara (2005) e Fundão (2006) e a Usina Mauá (2012) no rio Tibagi em parceria da COPEL com a Eletrosul (ORTEGA, 2016).

Para o estado do Paraná foi importante a parceria com o governo federal, que criou as condições mínimas necessárias para obter financiamentos externos que viabilizassem a construção de grandes obras de infraestrutura necessárias à industrialização do estado. Hoje o estado conta com um parque hidrelétrico de grandes dimensões, com grandes empreendimentos como no Rio Iguaçu: Foz do Areia, Segredo, Caxias, Salto Osório e Salto Santiago; nos rios da fronteira: Paranapanema, Xavantes, Salto Grande, Canoas, Capivara, Taquaruçu e Rosana; e no rio Paraná: a Usina de Itaipu. A COPEL opera 35 usinas próprias e participa em outras 10 usinas, sendo 21 hidrelétricas, 22 eólicas e 2 termoelétricas, com capacidade instalada total de $5.828 \mathrm{MWh}$ e garantia física de 2.715,7 MWh médios. Em 2018, a produção líquida de energia foi de 19.362,4 GWh (COPEL, 2018b).

Segundo o Banco de Informações de Geração- BIG da ANEEL (2020), o Paraná é responsável pela geração de 19.300.654,12 kWh de energia, correspondendo a 11,32\% do total gerado no Brasil, ficando atrás apenas de São Paulo (15,78\%), Pará (13,65\%) e Minas Gerais (12,21\%). O Paraná possui 229 empreendimentos em operação, 6 em construção e previsão de início de mais 19 para adição de $402.190 \mathrm{kWh}$ na capacidade de geração do Estado. A hidrelétrica Itaipu, localizada em Foz do Iguaçu - PR, tem potência para gerar 7.000.000 kWh de energia, só 
na parte brasileira. Apesar de já ser destaque na geração de energia, tem potencial para crescer e explorar várias fontes de energia, como eólica, solar e biomassa.

\section{METODOLOGIA}

Esta pesquisa tem caráter qualitativo caracterizada como descritiva e foi formulada a partir de referências e pesquisa bibliográfica.

\section{RESULTADOS}

Nesta parte do trabalho é apresentado um panorama do setor elétrico brasileiro e paranaense analisando o potencial de geração de energia por fontes alternativas bem como políticas sustentáveis e desafios para o setor.

\subsection{PANORAMA DO SETOR ELÉTRICO}

De acordo com Freitas e Soito (2008), a geração de energia elétrica no Brasil é extremamente dependente dos regimes hidrológicos das bacias hidrográficas. Existe um desequilíbrio regional na disponibilidade de água. Mas o Brasil vem diminuindo a geração de energia por fonte hidráulica ao longo dos anos, e aumentando a geração oriunda das fontes alternativas. Em 1999, 93\% do consumo era abastecido por usinas hidrelétricas. Esse número reduziu significativamente no início do século XXI. A Tabela 1 apresenta a participação das principais fontes na geração de energia elétrica no Brasil de 2013 a 2017.

Tabela 1- Participação (\%) das fontes de energia na geração de energia elétrica no Brasil de 2013

\begin{tabular}{l|c|c|c|c|c}
\multicolumn{1}{c}{ Fonte } & $\mathbf{2 0 1 3}$ & $\mathbf{2 0 1 4}$ & $\mathbf{2 0 1 5}$ & $\mathbf{2 0 1 6}$ & $\mathbf{2 0 1 7}$ \\
\hline Hidráulica & 68,50 & 63,24 & 61,89 & 65,80 & 63,08 \\
Gás Natural & 12,08 & 13,73 & 13,68 & 9,76 & 11,16 \\
Derivados do Petróleo & 3,87 & 5,34 & 4,41 & 2,09 & 2,16 \\
Carvão & 2,59 & 3,11 & 3,24 & 2,94 & 2,76 \\
Nuclear & 2,71 & 2,60 & 2,53 & 2,74 & 2,68 \\
Biomassa & 6,96 & 7,62 & 8,16 & 8,51 & 8,40 \\
Eólica & 1,15 & 2,07 & 3,72 & 5,78 & 7,21 \\
Outras & 2,14 & 2,29 & 2,37 & 2,38 & 2,55 \\
\hline Total (GWh) & 570.835 & 590.542 & 581.228 & 578.898 & 587.962 \\
\hline
\end{tabular}

Fonte: Elaborada pela autora com base em EPE (2018).

Em 2013, 68,5\% da geração de energia era hidráulica, em 2014 passou para 63,24\%, em 2015 61,9\%, em 2016 houve um aumento para aproximadamente 66\%, e em 2017 caiu para 63\%, 
com queda de 2,63\% de 2016 para 2017 (EPE, 2018). Em 2020, segundo a ANEEL (2020), esse percentual estava em $61,04 \%$ considerando a potência instalada. A geração de energia eólica representava 1,15\% da geração total de energia no Brasil em 2013. Em 2015 esse percentual subiu para 3,72\%, e em 2017 atingiu 7,2\%, representando um aumento de 26,5\% entre 2016 e 2017 e em 2020 atingiu 8,66\%. Já a energia gerada pela biomassa, em 2013 representava 6,96\%, em 2015 passou para 8,15\% e em 2017 foi para 8,40\%, representando um aumento de 0,3\% em relação a 2016 e em 2020 atingiu 8,40\%. (EPE, 2018; ANEEL, 2020).

Para a ANEEL (2008), a redução da participação das usinas hidrelétricas é devida a três fatores: necessidade da diversificação da matriz elétrica para aumentar a segurança do abastecimento; dificuldade em ofertar novos empreendimentos hidráulicos pela ausência da oferta de estudos e inventários; e o aumento de entraves jurídicos que protelam o licenciamento ambiental de usinas de fonte hídrica.

Em 2017, 63,1\% de toda energia gerada no Brasil era por fonte hidráulica, 11,16\% era de gás natural, 8,4\% era oriunda de biomassa ${ }^{5}, 7,21 \%$ de eólica, 2,76\% carvão, 2,68\% nuclear, 2,16\% petróleo, além de outras fontes ${ }^{6}$. A geração de energia nuclear está estabilizada ao longo dos anos, e gás natural e petróleo apresentaram tendência de queda nos últimos anos (EPE, 2018). Segundo a ANEEL (2020), em potência instalada em 2020, 61,04\% era hídrica, 14,70\% era fóssil, 8,66\% eólica, $8,41 \%$ biomassa, $1,50 \%$ solar e $1,13 \%$ nuclear.

Segundo a EPE (2018), em 2017 o Brasil se encontrava como $10^{\circ}$ maior consumidor de energia elétrica do mundo. Embora o Brasil apresentou dois anos de queda no consumo de energia elétrica, devido principalmente a desaceleração econômica, em 2017 o consumo aumentou 1,2\% em relação a 2016. O consumo de energia elétrica por habitante no Brasil, ao longo dos últimos anos, está em torno de 2,5 kWh. Em publicação de 2008, a ANEEL (2008) informou que de 1970 a 2007, a tendência foi de expansão do consumo global de energia no Brasil e de 1990 a 2007, o crescimento acumulado foi de $69 \%$, com o consumo total passando de 127,596 milhões de tep ${ }^{7}$ para 215,565 milhões de tep.

As regiões brasileiras, devido às grandes diferenças existentes, também apresentam geração e consumo de energia distintas. A Tabela 2 mostra a participação relativa de cada região na geração e no consumo de energia elétrica brasileira de 2013 a 2017.

\footnotetext{
${ }^{5}$ Biomassa: através de lenha, bagaço de cana e lixívia.

${ }^{6}$ Outras fontes são: gás de coqueria, outras secundárias, outras não renováveis, outras renováveis e solar.

7 Tep: toneladas equivalentes de petróleo.
} 
Tabela 2- Participação das regiões brasileiras na geração e consumo de energia elétrica de 2013 a 2017

\begin{tabular}{|c|c|c|c|c|c|}
\hline Região & 2013 & 2014 & 2015 & 2016 & 2017 \\
\hline \multicolumn{6}{|c|}{ Geração de energia } \\
\hline Norte & 12,57 & 13,67 & 14,99 & 12,47 & 16,12 \\
\hline Nordeste & 14,00 & 16,33 & 16,22 & 16,08 & 16,33 \\
\hline Sudeste & 33,88 & 30,69 & 28,95 & 31,17 & 31,20 \\
\hline Sul & 27,44 & 27,48 & 28,68 & 29,58 & 25,20 \\
\hline Centro-Oeste & 12,11 & 11,83 & 11,16 & 10,70 & 11,15 \\
\hline \multicolumn{6}{|c|}{ Consumo de energia } \\
\hline Norte & 6,52 & 6,82 & 7,24 & 7,42 & 7,39 \\
\hline Nordeste & 17,21 & 17,00 & 17,00 & 17,22 & 17,07 \\
\hline Sudeste & 51,84 & 51,07 & 50,63 & 50,02 & 49,77 \\
\hline Sul & 17,36 & 17,86 & 17,65 & 17,85 & 18,19 \\
\hline Centro-Oeste & 7,07 & 7,25 & 7,48 & 7,49 & 7,58 \\
\hline
\end{tabular}

Fonte: Elaborada pela autora com base em EPE (2018).

Em 2017, a região Norte produzia 16,12\% da energia total gerada no Brasil, a região Nordeste 16,33\%, o Sudeste contribuía com 31,20\%, Sul com 25,2\% e Centro-Oeste com apenas 11,15\%. Entre 2016 e 2017, a região Norte aumentou a geração de energia em 31,2\%, já a região Sul reduziu em $13,4 \%$.

Já com relação ao consumo de energia, a região Sudeste era líder em 2017 com 49,77\% do total consumido no Brasil, seguido da Sul com 18,19\%, Nordeste com 17,07\%, e Centro-Oeste e Norte, com 7,58\% e 7,39\% respectivamente. As regiões que mais aumentaram o consumo de energia de 2016 para 2017 foram Sul e Centro-Oeste, com 3,1\% e 2,4\% respectivamente. Com relação ao consumo de energia por habitante, a região Sul, em 2017, estava em torno de 2,86 kWh, na região Sudeste 2,66 kWh, no Centro-Oeste 2,22 kWh, no Norte 1,91 kWh e no Nordeste 1,39 $\mathrm{kWh}$. Esse fato reflete a atividade econômica e a capacidade produtiva dos habitantes dessas regiões (EPE, 2018). A região Sul aumentou o seu consumo de energia de 2013 para 2014, reduziu até 2016, voltando a aumentar em 2017, reflexo da situação vivenciada pela economia brasileira no período.

Dentre os estados brasileiros, o estado do Paraná foi o maior gerador de energia por muitos anos. A Tabela 3 apresenta a participação do Paraná na geração e no consumo de energia elétrica frente ao Brasil e a região Sul de 2013 a 2017.

De 2013 para 2017 o Paraná reduziu a geração de energia em 6,41\%. Em 2013 a participação do Paraná na geração nacional de energia era 18,15\%, em 2014 caiu para 16,74\%, em 2015 apresentou pequeno aumento para 17,10\%, em 2016 aumentou para 18,98\%, reduzindo no ano seguinte para 16,47\%. Em relação à região Sul, o Paraná gerava 66,14\% em 2013 passando para $65,33 \%$ em 2017. Apresentou acentuada queda na participação até 2015, se recuperando 
desde então. Na geração de energia, o estado do Paraná contava em 2020 com 229 empreendimentos em operação gerando 19.300.654,12 kWh de energia. Desses, 123 eram de fonte hídrica, 1 eólica, 4 fotovoltaica e 101 termoelétrica. Outros estados destaques eram São Paulo, Rio de Janeiro, Minas Gerais e Pará. Segundo a ANEEL (2020), em 2020 o Paraná era o quarto maior estado na geração de energia elétrica do Brasil, ficando atrás apenas de São Paulo, Pará e Minas Gerais.

Tabela 3- Participação do estado do Paraná na geração e consumo de energia elétrica de 2013 a 2017

\begin{tabular}{l|c|c|c|c|c}
\hline \multicolumn{7}{c|}{ Paraná } & $\mathbf{2 0 1 3}$ & $\mathbf{2 0 1 4}$ & $\mathbf{2 0 1 5}$ & $\mathbf{2 0 1 6}$ & $\mathbf{2 0 1 7}$ \\
\hline \multicolumn{7}{c}{ Geração de energia } \\
\hline Relação Brasil & 18,15 & 16,74 & 17,10 & 18,98 & 16,47 \\
Relação região Sul & 66,14 & 60,89 & 59,62 & 64,17 & 65,33 \\
\hline \multicolumn{7}{c}{ Consumo de energia } \\
\hline Relação Brasil & 8,62 & 6,40 & 6,41 & 6,41 & 6,58 \\
Relação região Sul & 36,11 & 35,99 & 36,35 & 35,91 & 36,15 \\
\hline
\end{tabular}

Fonte: Elaborada pela autora com base em EPE (2018).

Dos estados da região Sul, o estado do Paraná era o que mais consumia energia em 2017, com participação de 36,15\%, seguido do Rio Grande do Sul com 35,2\% e Santa Catarina com 28,6\%. O estado do Paraná reduziu o seu consumo de energia de 2014 para 2016 em 2,60\%, voltando a aumentar em 2017 3,8\%. De 2013 a 2017 o aumento no consumo foi de 5,84\%. Em 2017 o Paraná foi responsável por consumir 6,58\% do total de consumo de energia no Brasil, ficando atrás apenas de São Paulo, Minas Gerais e Rio de Janeiro, (EPE, 2018).

\subsection{POLÍTICAS E DESAFIOS PARA A GERAÇÃO DE ENERGIA POR FONTES ALTERNATIVAS}

Embora o Brasil venha diversificando sua matriz energética, a grande parte ainda é gerada pelas hidrelétricas. Segundo Kishinami (2017), o setor elétrico é um grande emissor de gases de efeito estufa (GEE) em todo o mundo. De acordo com o Painel Intergovernamental de Mudanças Climáticas das Nações Unidas- IPCC, a geração de eletricidade e calor foi responsável por aproximadamente 25\% das emissões globais em 2010. No Brasil, o setor elétrico foi responsável por $7 \%$ das emissões em 2014. 
De acordo com a EPE (2018), em 2013, o Brasil emitia 74,79 $\mathrm{MtCO}^{8}$ de gases do efeito estufa provenientes da geração de eletricidade. Esse número vem caindo ao longo do tempo. Em 2014 estava em 94,07 MtCO2, em 2015 caiu para 89,61 MtCO2, em 2016 para 64,44 MtCO2 e em 2017 estava em 61,14 MtCO2. Entre 2016 e 2017 as emissões de gases de efeito estufa caíram $5,1 \%$ na geração elétrica no país. Um dos motivos dessa queda é o maior incentivo que vem sendo dado em anos recentes às fontes de energia limpas e renováveis como eólica, solar e biomassa.

No estado do Paraná, por outro lado, segundo estudo de Sanquetta et al. (2017), as emissões de dióxido de carbono $(\mathrm{CO} 2)$ associadas ao consumo de energia elétrica aumentaram de 1,3 milhão de toneladas de CO2 equivalente (CO2e) em 2010 para 4,1 milhões em 2014. O aumento se deu, principalmente, pelo aumento da população, pelo maior consumo per capita de eletricidade e pelo uso mais intenso de fontes não renováveis na matriz elétrica. Grande parte dessas emissões foram oriundas do setor industrial, seguido do residencial e comercial. Além disso, o fator de emissões de dióxido de carbono estimadas para o Sistema Interconectado Nacional (SIN) aumentou de 0,0512 tCO2e por MWh em 2010 para 0,1355 em 2014, devido, sobretudo, ao aumento da participação dos insumos fósseis e das crises hídricas do período.

Diante do aumento da preocupação mundial com o aquecimento global, escassez de recursos e problemas climáticos, é preciso avanços tecnológicos e investimentos na geração de fontes alternativas e renováveis, como eólica, biomassa e solar, para que essas energias ganhem cada vez mais competitividade. O poder público precisa elaborar políticas eficientes para desenvolver as fontes alternativas.

As fontes de energia ditas como alternativas são renováveis e corretas ambientalmente. Permitem a diversificação da matriz energética, redução da dependência dos combustíveis fósseis e complementação à geração de energia hidráulica (ANEEL, 2008). É necessário diversificar e ampliar a geração de energia elétrica, ampliar a rede de captação, armazenamento e distribuição de água, instalar formas alternativas para aproveitar a água das chuvas, principalmente em regiões com secas extremas como o Nordeste, e sem dúvida, fazer planejamento a médio e longo prazo (JARDIM, 2015).

O Brasil possui um grande potencial em fontes renováveis como a energia eólica e a solar. As regiões litorâneas do Norte e Nordeste, vale do Rio São Francisco, Sudeste do Paraná e litoral sul do Rio Grande do Sul são bastante propícios para instalação de usinas eólicas. O Brasil tem

\footnotetext{
${ }^{8} \mathrm{MtCO} 2:$ Toneladas métricas de Dióxido de Carbono. É a medida padrão utilizada para quantificar as emissões de $\mathrm{CO} 2$.
} 
um volume de ventos duas vezes maior que a média mundial e baixa oscilação da velocidade. Além disso, a velocidade dos ventos é maior nos períodos de estiagem, podendo ser melhor aproveitado para suprir a queda de energia pela fonte hídrica (CEPEL, 2002; ANEEL, 2008).

Ademais, o Brasil é favorecido em termos de radiação solar, pois possui variação de radiação entre 8 e 22 megajoules por metro quadrado durante o dia e menores variações nos meses de maio à julho, com cerca de 8 a 18 megajoules por metro quadrado. A irradiação solar no Brasil é aproximadamente o dobro da média mundial. Destaca-se nesse cenário a região Nordeste e outras regiões como o vale do rio São Francisco na Bahia e as divisas dos estados de São Paulo, Paraná e Mato Grosso do Sul (CEPEL, 2002; ANEEL, 2008).

De acordo com pesquisa de Tiepolo et al. (2018), o estado do Paraná apresenta bons índices de irradiação solar, com destaque para a mesorregião Noroeste, que apresentou a maior média anual e menor variabilidade da irradiação global. Os altos índices de irradiação encontrados em toda a região Norte e em direção ao Oeste do estado fazem com que a média do estado seja bastante elevada, superior a grande parte dos países europeus como Alemanha, Reino Unido e França.

O Brasil também tem potencial para crescimento da energia gerada pela biomassa, principalmente pela cana-de-açúcar, já que o bagaço e a palha já são utilizados como fonte de energia. O volume já produzido de cana e o potencial de crescimento permitem demanda crescente para etanol e resíduos para produção de energia. Os estados de São Paulo, Minas Gerais e Paraná são destaques na produção de cana. Além disso, o período de safra da cana coincide com o período de estiagem na região Sudeste, onde estão as principais hidrelétricas do país. A energia elétrica gerada pela biomassa nesse período pode permitir auxílio na preservação dos reservatórios das usinas (ANEEL, 2008).

O primeiro instrumento legal de incentivos às fontes alternativas de energia no Brasil foi o PROINFA (Programa de Incentivo a Fontes Alternativas de Energia) instituído pela Lei 10.438 de 2002. O objetivo principal era aumentar a participação de usinas de energia eólica, biomassa e pequenas fontes hidrelétricas na matriz de energia elétrica (BRASIL, 2002). Para Morais (2015), esse programa funcionou como um instrumento para complementar a necessidade de eletricidade não atingida pela geração hidrelétrica.

Outro programa foi o Luz Para Todos, criado em 2003 pelo Ministério de Minas e Energia, por meio do Decreto 4.873. Esse programa tinha por objetivo universalizar o acesso e o uso de energia elétrica até o ano de 2010 e levar energia elétrica para a população que residia no interior do país e que ainda não possuía acesso (BRASIL, 2003). O programa se orientava por meio de três 
iniciativas: ampliação das redes de distribuição, implantação de sistemas de geração descentralizada com redes isoladas e sistemas de geração individuais. No programa foram instalados diversos sistemas fotovoltaicos em vários estados, como por exemplo, no estado da Bahia (MORAIS, 2015).

Em 2004 a Lei 10.848 criou o Leilão de Energia de Reserva para aumentar a segurança do fornecimento de energia, contratando uma capacidade extra. Essa lei também previu a participação de fontes alternativas nas licitações para suprimento das distribuidoras atendidas pelo Sistema Interligado Nacional- SIN e permitiu que essas empresas adquirissem energia elétrica proveniente de geração distribuída (BRASIL, 2004; MORAIS, 2015). Já em 2008 o Decreto 6.353 institui que a energia de reserva seria comprada através de leilões de energia, permitindo a incorporação de fontes de energias alternativas (BRASIL, 2008). Em 2008 também foi realizado o primeiro leilão de biomassa (ANEEL, 2008). Já em 2009, a Lei 11.977 que dispôs sobre o Programa Minha Casa Minha Vida autorizou o custeio, no âmbito do programa, da aquisição e instalação de equipamentos de energia solar (BRASIL, 2009).

Em 2007 foi criado o PAC- Programa de Aceleração Econômica com previsão de investimentos em infraestrutura em vários eixos no valor de 657,4 bilhões até 2010 . Esse programa contou com investimentos no setor elétrico para evitar apagões e novos problemas. Dentre as obras previstas estavam as hidrelétricas de Santo Antônio, Jirau, e Belo Monte (BRASIL, 2012). O programa PAC foi elaborado em 3 edições. O PAC 1 do período de 2007 a 2010, o PAC 2 de 2011 a 2014 e o PAC 3 de 2015 a 2018. O PAC 1 iniciou vários empreendimentos em usinas termoelétricas e exploração de petróleo, gasodutos e transporte de gás natural. No segmento de proteção ambiental e sustentabilidade, apenas houve investimentos em combustíveis renováveis como álcooldutos e refinarias. Estavam previstos 13,3 bilhões de reais na construção de mais de 100 usinas de etanol e biodiesel e outros 4,1 bilhões na construção de dois álcooldutos: um entre Senador Canedo (GO) e São Sebastião (SP) e outro entre Cuiabá (MT) e Paranaguá (PR). Essas ações contribuíram para estimular a produção de biomassa no país. Mas em termos de geração de energia por outras fontes alternativas, praticamente não houve investidas (BRASIL, 2012).

No PAC 2 estavam previstos 1,104 trilhões para serem investidos no período 2011-2014. Foram feitas mais de 5 mil $\mathrm{km}$ de rodovias, mais de mil $\mathrm{km}$ de ferrovias, 30 empreendimentos em portos brasileiros e mais de 538 mil ligações de energia elétrica para pessoas do campo, em assentamentos da reforma agrária, aldeias indígenas, comunidades quilombolas e ribeirinhas, entre outros investimentos em saneamento, água, etc. (BRASIL, 2014). 
No eixo de energia, o PAC 2 incluiu 15.908 MWh no parque gerador brasileiro. As usinas hidrelétricas de Santo Antônio e Jirau do estado de Rondônia entraram em operação nesse período. O Sistema Interligado Nacional foi expandido com 51 linhas de transmissão, totalizando 15.312 $\mathrm{km}$ de extensão e 52 subestações. Foram totalmente concluídos projetos de interligação, como o da Interligação Madeira e a Interligação Tucuruí-Macapá-Manaus, instaladas 108 usinas eólicas entre os estados da Bahia, Ceará, Rio Grande do Norte, Rio Grande do Sul, entre outros, e 32 usinas térmicas a biomassa entre os estados de Alagoas, Goiás, Minas Gerais, Mato Grosso, Mato Grosso do Sul, entre outros. Além disso, foram feitos 28 empreendimentos para exploração e produção de petróleo e gás, 21 empreendimentos para refino e petroquímica, 11 obras para fertilizantes e gás natural, 3 empreendimentos para combustíveis renováveis. Estavam em construção no período 8 hidrelétricas, 3 termoelétricas, 89 usinas eólicas e 4 pequenas centrais hidrelétricas (BRASIL, 2014).

O PAC 3 estimou investimentos na ordem de 603 bilhões de reais. No eixo de geração e transmissão de energia elétrica entraram em operação 21.804 MWh até junho de 2018 e 15 unidades geradoras na UHE Belo Monte. Foi concluído a UHE São Manoel, 275 usinas de energia eólica entre os estados do Rio Grande do Norte, Bahia, Ceará, Maranhão, Paraíba, Pernambuco, Piauí e Rio Grande do Sul, e 8 usinas fotovoltaicas nos estados da Bahia, São Paulo, Piauí e Minas Gerais. Além disso, foram instalados 11.928 quilômetros de linhas de transmissão e $18.029 \mathrm{MWh}$ de capacidade de transformação de energia em subestações (BRASIL, 2018).

Embora as versões do PAC tenham contribuído para vários empreendimentos no setor de energias alternativas, surgiram muitos problemas e críticas, principalmente no atraso das obras, na paralisação de muitas delas e nos casos de corrupção.

Em 2019, o Ministério da Economia, no governo de Jair Bolsonaro, lançou um programa chamado Pró-Infra. Esse programa pretendeu investir em infraestrutura para gerar crescimento econômico com apoio privado. Este projeto contou com três principais eixos: a) reduzir a participação do governo em projetos de infraestrutura; b) desenhar mercados setoriais que permitam o irrestrito investimento privado; e c) análise de projetos e planejamento de longo prazo. Dentro do primeiro eixo uma ação seria a desconcentração do estoque do PAC e interrupção do fluxo de novos projetos; no segundo eixo, redução dos subsídios e encargos na tarifa de energia elétrica; e no terceiro, criação da metodologia de priorização de projetos por critérios econômicos. No entanto não houve menção no plano do programa projetos e investimentos para fontes alternativas, apenas para construção de hidrelétricas (BRASIL, 2019a). 
Em meados de 2019, o novo governo brasileiro lançou também o Plano Plurianual para o exercício 2020/2023 com slogan "Planejar, Priorizar e Avançar”. Nesse plano, as áreas definidas como prioritárias foram: infraestrutura, defesa, segurança pública, recursos hídricos, saúde e educação infantil. Entre os projetos prioritárias estavam: Programa Nuclear da Marinha, Integração do Rio São Francisco com as Bacias do Nordeste Setentrional (Eixo Leste) e Projeto de Integração do Rio São Francisco com Bacias Hidrográficas do Nordeste Setentrional (BRASIL, 2019b).

No Plano Plurianual 2020/2013 foram elaborados 6 eixos de atuação estratégica, dentre eles o eixo ambiental e o eixo de infraestrutura. No eixo ambiental o objetivo foi "garantir a sustentabilidade dos recursos naturais, conciliando o progresso econômico com a preservação do meio ambiente". Já no eixo de infraestrutura, o objetivo foi “destravar os gargalos logísticos do país e prover as condições essenciais de transporte, energia e mineração, priorizando investimentos públicos de forte impacto regional e local” (BRASIL, 2019b, p. 26-27). No eixo ambiental estavam previstos gastos no montante de 139,8 milhões e no eixo de infraestrutura 384,2 milhões, totalizando no plano 6,8 trilhões de reais.

Comparando os investimentos feitos ao longo dos programas PAC, o Plano Plurianual 2020/2023 apresenta redução significativa no montante a ser investido na totalidade e no eixo de infraestrutura. Um dos motivos é a desaceleração econômica e a retomada do crescimento, com foco no ajuste das contas públicas, e outro é a concepção do modelo de governança implantado pelo novo governo, baseado no apoio do setor privado e redução do setor público na economia.

Especificamente no estado do Paraná, o Decreto 11.671 de julho de 2014 instituiu o Programa Paranaense de Energias Renováveis cujo objetivo era promover e incentivar a produção e o consumo de energia a partir de fontes renováveis, em especial a biomassa, a eólica e a solar. Esse Programa foi alterado pelo Decreto 8.673 de janeiro de 2018 que especificou que o Fomento Paraná e o Banco de Desenvolvimento do Extremo Sul- BRDE seriam agentes parceiros oferecendo linhas específicas de financiamento para os empreendimentos de geração, transporte, transmissão e consumo de energia renovável (PARANÁ, 2014, 2018a).

Em novembro de 2018 foi publicado o Decreto 11.538 que tratou sobre a criação do Projeto Smart Energy Paraná. O projeto Smart Energy buscou a organização e a centralização de ações de curto, médio e longo prazo no setor de geração de energia por fontes renováveis e sua conexão às redes inteligentes, além de fomentar instrumentos que possibilitem às instituições públicas e 
privadas a adotarem estratégias comuns para pesquisa, produção, comercialização, uso e disseminação de novas tecnologias (PARANÁ, 2018a).

Ainda em 2018, a Lei 19.595 de 12 de julho institui benefícios para incentivar o aproveitamento de energia elétrica produzida por microgeradores e minigeradores de energia distribuída no estado do Paraná. Esta lei isentou de ICMS o excedente da microgeração de energias renováveis. O Paraná aderiu ao convênio do Conselho Nacional de Política Fazendária- Confaz concordando em não cobrar a alíquota de $29 \%$ de quem gera mais energia do que precisa e devolve ao sistema elétrico, mas condicionou o incentivo ao prazo de 48 meses (PARANÁ, 2018b).

Além desses projetos e leis de iniciativa pública, a empresa privada Enerbios Consultoria em Energias Renováveis e Meio Ambiente, que tem sede em Curitiba, em parceria com a Enercons e Innovent lançaram o projeto "Complexo de Geração Eólica Palmas II”, com investimento previsto de 1,2 bilhão no município de Palmas, região Sudoeste do Paraná. Será a segunda usina eólica instalada no município de Palmas com potência quase 80 vezes maior ao primeiro parque construído pela COPEL em 1999, até então, o único parque eólico do Sul do País. O empreendimento prevê oito parques eólicos, sendo eles Campo Alegre, Pederneiras, Santa Cruz, Santa Maria, São Francisco, Taipinha, Tradição e Tradição Piloto, que deverão estar interligados à subestação de Palmas, através de linha de transmissão de 28 quilômetros, com traçado previsto para faixa de domínio da PRC-280 (ENERCONS, 2020).

Diante do aumento da preocupação mundial com o aquecimento global, escassez de recursos, crises energéticas, e problemas climáticos, é necessário o desenvolvimento de fontes alternativas e renováveis para geração de energia. No caso brasileiro, soma-se a necessidade de reduzir a dependência da geração de energia hidrelétrica, haja vista os altos custos de instalação, impactos ambientais e problemas estruturais. Percebeu-se que até 2018 os investimentos feitos pelo PAC foram bastante expressivos no que diz respeito ao incentivo às fontes alternativas de energia. Porém, o Plano Plurianual elaborado em 2019 com vigência para 2020/2023 apresentou redução significativa do montante a ser investido. No caso paranaense, o governo vem se esforçando para combinar esforços com a iniciativa privada para promover projetos que busquem incentivar as fontes alternativas de energia. Salienta-se a necessidade da continuidade dos investimentos em fontes mais corretas ambientalmente já que a demanda por energia é crescente e é necessário desenvolvimento mais sustentável para os próximos anos. 


\section{CONSIDERAÇÕES FINAIS}

Este trabalho se propôs a realizar um panorama do setor de energia elétrica no Brasil e no estado do Paraná a fim de analisar políticas e desafios para a geração de energia por meio de fontes alternativas e mais sustentáveis. Hoje $61,04 \%$ da potência instalada no Brasil é para geração de energia hidráulica, 14,70\% ainda é de origem fóssil e 1,13\% ainda é nuclear, mas 8,66\% é eólica, $8,41 \%$ é biomassa e $1,50 \%$ solar, de acordo com a ANEEL (2020).

No estado do Paraná, existiam 229 empreendimentos em operação em 2020 gerando mais de 19 bilhões de kWh de energia. Desses, 123 eram de fonte hídrica, 1 eólica, 4 fotovoltaica e 101 termoelétrica. O Paraná era o quarto maior estado na geração de energia elétrica do Brasil, ficando atrás apenas de São Paulo, Pará e Minas Gerais (ANEEL, 2020). As fontes alternativas estão cada vez mais sendo implantadas no Brasil, no entanto, o desafio ainda é grande dado o potencial que possui, principalmente para o estado do Paraná.

Apesar da geração de energia hidráulica apresentar a vantagem de contar com recurso abundante, ela possui altos custos da instalação das usinas, tempo longo para início de operação, forte impacto social e ambiental pelas inundações e dependência de regime regular de chuvas. Além disso, muitos estudos afirmam que os reservatórios das usinas hidrelétricas geram emissões de gases causadores do efeito estufa.

De acordo com a EPE (2018), o Brasil vem diminuindo as emissões de poluentes provenientes da geração de eletricidade, já que esse número vem caindo ao longo do tempo. Um dos motivos dessa queda é o maior incentivo que vem sendo dado em anos recentes às fontes de energia limpas e renováveis como eólica, solar e biomassa. O estado do Paraná, por outro lado, está no caminho contrário, pois aumentou as emissões de dióxido de carbono entre 2010 e 2014. $\mathrm{O}$ aumento se deu, sobretudo, pelo aumento da população, pelo maior consumo per capita de eletricidade e pelo uso mais intenso de fontes não renováveis na matriz elétrica.

As fontes de energia alternativas são renováveis e corretas ambientalmente e devem ser preferidas às fontes fósseis que degradam ao meio ambiente. Fontes alternativas como energia eólica, solar e por biomassa permitem a diversificação da matriz energética, redução da dependência dos combustíveis fósseis e complementação à geração de energia hidráulica. É necessário diversificar e ampliar a geração de energia elétrica e sem dúvida, fazer planejamento a médio e longo prazo. O Brasil, assim como o estado do Paraná, possuiu grande potencial para ampliação das energias mais sustentáveis, pois conta com regiões propícias com ventos e raios solares acima da média. 
O primeiro instrumento legal de incentivo às energias renováveis no Brasil foi o PROINFA em 2002. Depois outros tiveram algum papel em desenvolver essas fontes, como o Luz para Todos e as versões do PAC. No estado do Paraná dois programas são destaques, o Programa Paranaense de Energias Renováveis e Projeto Smart Energy. No entanto, ainda é preciso mais investimentos e desenvolvimento de tecnologias para que essas energias sejam mais baratas e atraentes, além de políticas públicas coordenadas nesse sentido.

Este artigo pretende contribuir com o debate na literatura sobre esta temática, sem, no entanto, esgotar as discussões. O desenvolvimento de fontes alternativas de energia será cada vez mais uma necessidade para que as futuras gerações possam conviver com harmonia e recursos adequados para manutenção da vida.

\section{REFERÊNCIAS}

ANEEL- Agência Nacional de Energia Elétrica. Atlas da Energia Elétrica do Brasil. $3^{\circ}$ edição. 2008. Disponível em: <http://www2.aneel.gov.br/arquivos/PDF/atlas3ed.pdf>. Acesso em: 07 dez. 2019.

BIG- Banco de Informações de Geração. 2020. Disponível em:

<https://www2.aneel.gov.br/aplicacoes/capacidadebrasil/capacidadebrasil.cfm>. Acesso em: 17 mar. 2020.

BRASIL. Decreto-Lei no 24. 653, de 10 de julho de 1934. Decreta o Código de Águas. Diário Oficial da União, Brasília, Distrito Federal, 1934. Disponível em:

<http://www.planalto.gov.br/ccivil_03/decreto/D24643.htm>. Acesso em: 13 set. 2019.

. Lei $\mathrm{n}^{\circ} 10.438$, de 26 de abril de 2002. Dispõe sobre a expansão da oferta de energia elétrica emergencial e da outras providências. Diário Oficial da União, Brasília, Distrito Federal, 2002. Disponível em: <http://www.planalto.gov.br/ccivil_03/LEIS/2002/L10438.htm>. Acesso em: 13 set. 2019.

Decreto $n^{\circ} 4.873$, de 11 de novembro de 2003. Institui o Programa Nacional de Universalização do Acesso e Uso da Energia Elétrica - "LUZ PARA TODOS" e dá outras providências. Diário Oficial da União, Brasília, Distrito Federal, 2003. Disponível em: < http://www.planalto.gov.br/ccivil_03/decreto/2003/D4873.htm >. Acesso em: 04 dez. 2019.

Lei ${ }^{\circ} 10.848$, de 15 de março de 2004. Dispõe sobre a comercialização de energia elétrica e da outras providências. Diário Oficial da União, Brasília, Distrito Federal, 2004. Disponível em: <http://www.planalto.gov.br/ccivil_03/_Ato2004-2006/2004/Lei/L10.848.htm>. Acesso em: 08 out. 2019. 


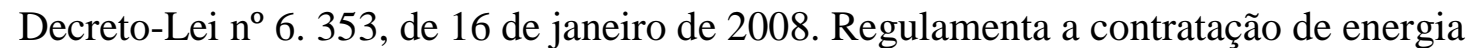
de reserva e da outras providências. Diário Oficial da União, Brasília, Distrito Federal, 2008. Disponível em: <http://www.planalto.gov.br/ccivil_03/_Ato2007-2010/2008/Decreto/D6353.htm Acesso em: 13 set. 2019.

. Lei no 11. 977, de 7 de julho de 2009. Dispõe sobre o Programa Minha Casa, Minha Vida - PMCMV e da outras providências. Diário Oficial da União, Brasília, Distrito Federal, 2009. Disponível em: <http://www.planalto.gov.br/ccivil_03/_Ato20072010/2009/Lei/L11977.htm Acesso em: 05 dez. 2019.

. Ministério do Planejamento. $1^{\circ}$ Balanço Completo do PAC - 4 anos (2007 a 2010). 2012. Disponível em: < http://www.pac.gov.br/sobre-o-pac/publicacoesnacionais >. Acesso em: 04 dez. 2019.

. Ministério do Planejamento. 11 Balanço Completo do PAC 2- 4 anos (2011 a 2014). 2014. Disponível em: < http://www.pac.gov.br/sobre-o-pac/publicacoesnacionais >. Acesso em: 04 dez. 2019.

Ministério do Planejamento. $7^{\circ}$ Balanço do PAC - 4 anos (2015 a 2018). 2018. Disponível em: 〈http://www.pac.gov.br/sobre-o-pac/publicacoesnacionais > . Acesso em: 04 dez. 2019.

. Ministério da Economia. Pró-Infra. 2019a. Disponível em: <http://www.mdic.gov.br/images/REPOSITORIO/Livreto_Pro-Infra.pdf>. Acesso em: 05 dez. 2019.

Ministério da Economia. Plano Pluri Anual 2020-2023. 2019b. Disponível em: $<$ https://www.camara.leg.br/internet/comissao/index/mista/orca/ppa/ppa_2020_2023/propost a/MensagemPres.pdf $>$. Acesso em: 05 dez. 2019.

CEPEL- Centro de Pesquisa em Energia Elétrica. Atlas do potencial eólico brasileiro. 2002. Disponível em:

<http://www.cresesb.cepel.br/publicacoes/download/atlas_eolico/Atlas\%20do\%20Potencial\%20 Eolico\%20Brasileiro.pdf >. Acesso em: 29 nov. 2019.

COPEL- Companhia Paranaense de Energia. Conselho Estadual de Energia do Estado do Paraná. Modelagem energética do Paraná. Curitiba: COPEL, 1982.

. História da Energia no Paraná. 2018a. Disponível em:

<https://www.copel.com/hpcopel/root/nivel2.jsp?endereco=\%2Fhpcopel\%2Froot\%2Fpagcopel2. nsf\%2F0\%2F938F473DCEED50010325740C004A947F>. Acesso em: 09 dez. 2019.

Relatório Integrado 2018. 2018b. Disponível em:

<https://www.copel.com/hpcopel/root/sitearquivos2.nsf/arquivos/relato_integrado_2018/\$FILE/ Relato\%20Integrado\%20Copel\%202018.pdf>. Acesso em: 12 dez. 2019.

ENERCONS. Complexo Eólico Palmas II, 2020. Disponível em:

<http://enercons.com.br/2019/10/18/complexo-eolico-palmas-ii-e-aprovado-pela-alep-e-vaipara-sancao-do-governo/>. Acesso em: 18 mai. 2020. 
EPE- Empresa de Pesquisa Energética. Consumo de Energia Elétrica. 2018. Disponível em: $<$ http://www.epe.gov.br/pt/publicacoes-dados-abertos/publicacoes/consumo-de-energia-eletrica >. Acesso em: 07 dez. 2018.

FRANCISCO, C. M. Connecting renewable power plant to the Brazilian transmission power system. The Institute of Brazilian Business and Public Management Issues, 2012. Disponível em:

<https://pdfs.semanticscholar.org/8ad6/2a6478b52d26ed5b7a09b73e96d955beff37.pdf $>$ Acesso em: 12 set. 2019.

FREITAS, M. A. V.; SOITO, J. L. S. Energia e recursos hídricos. Parcerias Estratégicas, v. 13, n. 27, p. 177-216, 2008. Disponível em:

<http://seer.cgee.org.br/index.php/parcerias_estrategicas/article/view/331 >. Acesso em: 14 nov. 2019.

GASTALDO, M. M. Histórico da regulamentação do setor elétrico brasileiro. O setor elétrico, n. 36, p. 36-42, 2009.

GOMES, A. C. S. et al. BNDES 50 Anos e Historias Setoriais: O Setor Elétrico, 2002.

Disponível em:

<https://www.bndes.gov.br/SiteBNDES/export/sites/default/bndes_pt/Galerias/Arquivos/conheci mento/livro_setorial/setorial14.pdf>. Acesso em 07 out. 2019.

GUENA, A. M. O. Avaliação ambiental de diferentes formas de geração de energia elétrica. Dissertação (Mestrado em Ciências)- Universidade de São Paulo. 2007. Disponível em:

<https://www.teses.usp.br/teses/disponiveis/85/85134/tde-14052007-224500/pt-br.php >. Acesso em: 28 dez. 2018.

JARDIM, C. H. A" crise hídrica" no Sudeste do Brasil: aspectos climáticos e repercussões ambientais. Revista Tamoios, v. 11, n. 2, 2015. Disponível em: <https://www.epublicacoes.uerj.br/index.php/tamoios/article/view/16517>. Acesso em: 19 nov. 2019.

KISHINAMI, R. Impactos de mudanças na matriz elétrica brasileira. Instituto Escolhas: 2017. Disponível em: <http://escolhas.org/wpcontent/uploads/2017/04/FD_210x280mm_ENERGIA_14.pdf>. Acesso em: 08 out. 2019.

LORENZO, H. C. O setor elétrico brasileiro: passado e futuro.

Perspectivas, São Paulo, p. 147-170, 2001. Disponível em:

<https://repositorio.unesp.br/handle/11449/108151>. Acesso em: 08 out. 2019.

MAGAlHÃes, M. B. Paraná: política e governo. Curitiba: (Col. História do Paraná, $2^{\circ}$ edição eletrônica) Seed, 2017. Disponível em:

<http://bibliotecadigital.tse.jus.br/xmlui/bitstream/handle/bdtse/5317/2017_magalhaes_parana_p olitica_governo.pdf?sequence=1\&isAllowed=y $>$. Acesso em: $11 \mathrm{dez} .2019$. 
MORAIS, L. C. Estudo sobre o panorama da energia elétrica no Brasil e tendências futuras. Dissertação (Mestrado em Engenharia Elétrica) - Universidade Estadual de São Paulo, BauruSP, 2015. Disponível em: <https://repositorio.unesp.br/handle/11449/132645>. Acesso em: 13 dez. 2018.

ORTEGA, M. R. O Paraná na Era da Eletricidade. A Era da Eletricidade, 2016. Disponível em: < https://aeradaeletricidade.blogspot.com/2016/07/energia-parana.html>. Acesso em: 12 dez. 2019.

PARANÁ. Decreto no 11.538 , de 05 de novembro de 2018. Trata sobre a criação do Projeto Smart Energy Paraná. Casa Civil do Estado do Paraná, 2018a. Disponível em: $<$ https://www.legislacao.pr.gov.br/legislacao/pesquisarAto.do?action=exibir\&codAto $=210011 \&$ codTipoAto\&tipoVisualizacao=alterado $>$. Acesso em: 18 mai. 2020.

. Lei ${ }^{\circ} 19.595$, de 12 de julho de 2018. Institui benefícios para incentivar o aproveitamento de energia elétrica produzida por microgeradores e minigeradores de energia distribuída. Casa Civil do Estado do Paraná, 2018b. Disponível em:

$<$ https://www.legislacao.pr.gov.br/legislacao/pesquisarAto.do?action=exibir\&codAto=202386\&i $\underline{\text { ndice }=1 \& \text { totalRegistros }=44 \& \mathrm{dt}=18.4 .2020 .17 .57 .50 .131>}$. Acesso em: 18 mai. 2020 .

PIRES, J. C. L.; GOSTKORZEWICZ, J.; GIAMBIAGI, F. O cenário macroeconômico e as condições de oferta de energia elétrica no Brasil. Textos para Discussão, BNDES, Rio de Janeiro, n. 85, 2001. Disponível em: 〈https://web.bndes.gov.br/bib/jspui/handle/1408/14251>. Acesso em: 04 mar. 2020.

SANQUETTA, C. R. et al. Emissões de Dióxido de Carbono associadas ao consumo de energia elétrica no Paraná no período 2010-2014. BIOFIX Scientific Journal, v. 2, n. 1, p. 1-6, 2017. Disponível em: <https://revistas.ufpr.br/biofix/article/viewFile/50095/31999>. Acesso em: 10 dez. 2019.

SILVA, B. G. Evolução do setor elétrico brasileiro no contexto econômico nacional: uma análise histórica e econométrica de longo prazo. 2011. Tese de Doutorado. Universidade de São Paulo. Disponível em: <http://www.teses.usp.br/teses/disponiveis/86/86131/tde-12032012091848/en.php>. Acesso em: 04 out. 2019.

SOUZA, P. V. P. A energia elétrica e o desenvolvimento do Paraná. Revista Paranaense de Desenvolvimento, n, 87, p. 65-87, 1996. Disponível em:

<https://dialnet.unirioja.es/ejemplar/375561 >. Acesso em: 09 dez. 2019.

TIEPOLO, G. M. et al. Atlas de Energia Solar do Estado do Paraná- Resultados. Revista Brasileira de Energia Solar, v. 9, n. 1, p. 01-10, 2018. Disponível em: <https://rbens.emnuvens.com.br/rbens/article/view/229>. Acesso em: 12 dez. 2019.

VICHI, F. M.; MANSOR, M. T. C. Energia, meio ambiente e economia: o Brasil no contexto mundial. Química Nova, São Paulo, v. 32, n. 3, p. 757-767, 2009. Disponível em: <http://bdpi.usp.br/bitstream/handle/BDPI/12309/art_VICHI_Energia_meio_ambiente_e_econo mia_o_Brasil_2009.pdf?sequence=1\&isAllowed=y >. Acesso em: 28 dez. 2018. 